SciDioc

\section{The Effect of Cigarette Smoking on the Pain Induced by Elastomeric Separators in Patients Who are Candidate For Orthodontic Treatment}

Ghaith F Sahtout ${ }^{1 *}$, Ahmad S Burhan ${ }^{1}$, Fehmieh R Nawaya ${ }^{2}$

${ }^{1}$ Department of Orthodontics and DentofacialOrthopaedics, Faculty of Dentistry, Damascus University, Damascus, Syria.

${ }^{2}$ Department of Pediatric Dentistry, Faculty of Dentistry, Syrian Private University, Damascus Contryside, Syria.

\title{
Abstract
}

Objectives: Studying the effects of cigarette smoking on the pain induced by elastomeric separators in patients who need orthodontic treatment.

Materials and Methods: The research sample consisted of (40) patients, whose ages ranged between (20-27) years, in need of orthodontic treatment by fixed appliance, with a non-extraction treatment plan. The patients were distributed into two groups (smokers and non-smokers), smokers group consisted of patients who smoke more than 20 cigarettes (between 20 to 25) per day. The non-smoker group consisted of patients who never smoke any cigarette during their lifetime. After applying the elastomeric separation, the patients were asked to record their pain severity through a questionnaire, that contains a digital optical scale (VAS) including 0 (0 means no pain) to $10 \mathrm{~cm}) 10$ means the worst possible pain), after 1$)$ hour, (24) hours, and (48) hours and a week of elastomeric separators placement, in both rest and chewing modes, for each time. Mann-Whitney test was used to study the significance of the differences between the average pain amount and the two groups at the significance level of $(\mathrm{P}=0.05)$.

Results: 40 patients were evaluated for eligibility. Pain data were statistically analyzed. A statistical significance was found after all assessment points except after 7 days, in both chewing and rest.

Conclusion: Cigarette smoking may affect pain levels induced by elastomeric separators.

Keywords: Cigarette Smoking; Nicotine; Orthodontic Pain; Elastomeric Separators.

\section{Introduction}

Orthodontic treatment involves applying many forces to the periodontal ligament throughout its several stages, so orthodontic treatment is considered a painful procedure [1]. Patients undergoing orthodontic treatment may behold a considerable amount of disturbance, such as feelings of stress, burden, irritation of teeth, and even pain [2]. Clinical practice and modern research data signalize that patients may acclimate to persistent pain and annoyance with the development of treatment as the sensations cut out or at least mold from their center of awareness [3]. In order to supply an appropriate distance for the inserting oforthodontic bands, orthodontists usually insert elastomeric separators in the mesial and distal of the tooth. Elastomeric sepa- rators positioning is considered a distressing step for almost all patients [4]. Enforcing elastomeric separators breeds compression in the periodontal ligament which procures the excretion of inflammatory mediators, like prostaglandins and histamine, that induce free nerve endings resulting in the perception of pain [5, 6]. Subversive health outcomes may result from smoking, which is considered a pioneer problem nowadays. Many cigarette addicts are able to quit, on the other hand, equal numbers are not able to quit smoking. The neoteric knowledge in the neurobiology of nicotine dependence has defined several neurotransmitter systems that may take a part in the process of smoking conservation and retrogression. These implicate dopamine particularly, norepinephrine, 5-hydroxytryptamine, acetylcholine, endogenous opioids, gamma-aminobutyric acid (GABA), glutamate, and endocannabinoids [7]. Nicotine has some tranquilizer traits; it was

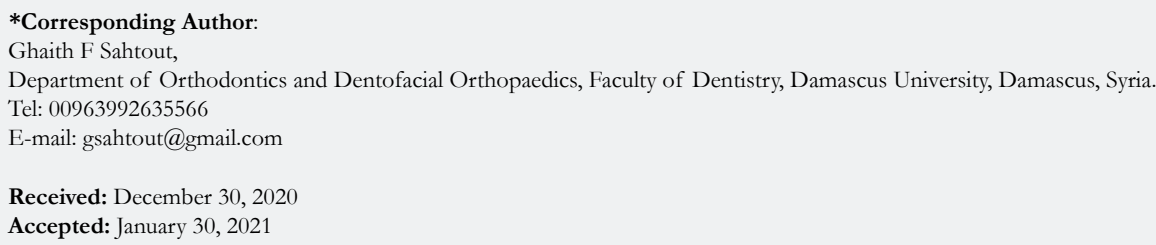

Citation: Ghaith F Sahtout, Ahmad S Burhan, Fehmieh R Nawaya. The Effect of Cigarette Smoking on the Pain Induced by Elastomeric Separators in Patients Who are Candidate For Orthodontic Treatment Int J Dentistry Oral Sci. 2021;8(2):1606-1609. doi: http://dx.doi.org/10.19070/2377-8075-21000318

Copyright: Ghaith F Sahtout ${ }^{\odot} 2021$. This is an open-access article distributed under the terms of the Creative Commons Attribution License, which permits unrestricted use, distribution and reproduction in any medium, provided the original author and source are credited. 
first discovered in feline visceral pain models. After that, it was propagated in abundant human and animal studies [8-10]. Nicotine affects both the central and peripheral nicotine acetylcholine receptors (nAChRs) $[9,11,12]$, this is where it gets its' analgesic effect. Other nAChR ligands also have study analgesic effects [1315]. In different circumstances, it's clinically proved that people who smoke have higher risks for having enhanced back pain and other chronic pain disorders [16-19]. Moreover, comparing smokers and non-smokers with chronic pain disorders has frequently dissected that smokers have higher pain outcomes and a higher effect on occupational and social function [19, 20]. This obvious paradox is not considered only as scientific interest but also has clinical relevance in looking after smokers in the perioperative period and smokers with chronic painful conditions.

\section{Objective}

To study the effect of cigarette smoking on the pain experienced in patients after elastomeric separators placement in rest and chewing modes.

\section{Materials and Methods}

\section{Study Design}

This study was a clinical controlled trial, studying the effect of cigarette smoking on the pain experienced in patients after elastomeric separators placement in rest and chewing modes. This study was approved by the institutional review board and an ethical review committee of Damascus University (Damascus-Syria) to conduct this study (NO 4118). The study was conducted in the Department of Orthodontics at Damascus University.

\section{Sample Size Calculation}

The sample size wascalculated using the G*Power 3.1.3 program. According to the data from Nóbrega et al., study (2), which effect size was 0.83 , and the study power is 80 percent, and the significance level of 0.05 . The sample size for each group depending on the program was 38 patients, taking into consideration the sample drop out, one patient was added to each group which made the total sample size 40 patients.

\section{Participants}

The sample was selected from patients who search for orthodontic treatment, at the Department of Orthodontic and DentofacialOrthopaedics at Damascus University, Faculty of Dentistry, Damascus, Syria. Data were collected from February 2018 to January 2020.

\section{Inclusion and Exclusion Criteria}

Inclusion criteria were: The smoking rate for patients in the smokers' group was not less than 20 cigarettes (between 20 to 25 cigarettes) per day (each cigarette contains $0.2 \mathrm{mg}$ nicotine or more). The non-smoker group consisted of patients who never smoke any cigarette during their lifetime. The ages of patients who are in need of orthodontic treatment by fixed appliance, with non-extraction treatment plan ranged between 20-27 years, good oral hygiene, no systemic or periodontal sickness, no intake of drugs that conflict with pain conception for at least 3 days before elastomeric separators placemen, right mandibular first molars and the existence of a healthful contact point of the mandibular first molars with each adjacent tooth. Exclusion criteria were: patients with health status or medication treatment that affected orthodontic treatment and periodontal health, poor oral hygiene. Patients were excluded from the study if any non-steroidal antiinflammatory medications or other drugs that have an analgesic effect were taken (acetaminophen, opioids, alcohol, etc ..). Failed to finish the questionnaire and patients who have had previous orthodontic treatment. Patients who reviewed the orthodontic department in the faculty of dentistry- Damascus University were examined by the investigator (G.S), 70 of them meet the inclusion criteria (40 non-smokers, 30 smokers). Microsoft Excel 2010 has been used to randomize the patients, this procedure has been done to each group separately. Based on the randomizing done by the program, 40 patients were selected to participate (20 non-smokers, 20 smokers). The objective and procedures were explained to patients via an information sheet. In the case of accepting to participate, the patients signed informed consent.

\section{Clinical Interventions}

0.5-mm elastomeric separators (Ortho Classic, 1300 NE Alpha Drive, McMinnville, Or, USA) were entered at the mesial and distal of each mandibular first molar for 7 days. A questionnaire including the assessment time points (after 24, 48 hours, and 7 days of elastomeric separator application). The elastomeric separators were inserted for all patients at 10 A.M. ( \pm 60 minutes). Furthermore, the later assessment time points were unified among patients. All clinical procedures were done by the same investigator (G.S).

\section{Pain measurement}

The measurement of pain in both groups at 1 hour, 24, 48 hours, and 7 days after elastomeric separator placement in two settings, rest and chewing modes. At each time point, evaluations were conducted using a questionnaire including a $10-\mathrm{cm}$ Visual Analogue Scale (VAS). Questions were rated on a 10-point scale, with 0 indicating no pain and 10 indicating severe pain. Instructions on how patients record their pain scores were explained to patients. Before every evaluation time point, further bite Instructions were demonstrated on a piece of bread that required a degree of pressure to be chewed. This step is essential to stimulate the mastication procedure and motivate the pain thus, to score the degree of pain accurately.

\section{Statistical analysis}

Mann-Whitney test was used to compare the mean pain scores between smokers and non-smokers in both chewing and rest modes. Normality distribution was checked using Shapiro-Wilk tests. All statistical analyses were done using the Statistical Package for the Social Sciences (IBM SPSS Inc. version.25, Chicago, III). Statistically significant was determined at $\mathrm{p}$ value $<0.05$.

\section{Results}

Forty patients were registered in this study, no dropouts occurred. Complete follow-ups were done for all patients and appropriate 
analyses were achieved. Descriptive statistics of the sample regarding gender and age are shown in Table 1.

Table 2 shows that pain intensity was significantly increased after 1 hour ( $p=003), 24$ hours $(p=0.000)$, and 48 hours $(p=001)$. No statistical significance was found after 7 days $(p=0.333)$, indicating that cigarette smoking increases the pain intensity during orthodontic treatment rest mode after assessment time points except after 7 days.

Table 3 shows that pain intensity was significantly increased after 1 hour ( $p=002), 24$ hours $(p=0.001)$, and 48 hours $(p=0.000)$. No statistical significance was found after 7 days $(p=0.752)$, indicating that cigarette smoking increases the pain intensity during orthodontic treatment rest mode after assessment time points except after 7 days.

In both groups, the peak of pain was observed after 24 hours with mean pain scores of $(8.25 \pm 0.786) \mathrm{cm}$ and $(7.25 \pm 0.910)$ $\mathrm{cm}$ for smokers and non-smokers respectively in chewing mode, and $(7.15 \pm 0.671) \mathrm{cm}$ and $(5.90 \pm 0.968) \mathrm{cm}$ for smokers and non-smokers respectively in rest mode.

\section{Discussion}

This study aims to evaluate the effect of cigarette smoking on pain in patients undergoing orthodontic treatment when apply- ing elastomeric separation in the comfort and chewing modes. The evaluation of the effect of smoking on pain has been studied in several studies, some of these studies showed that nicotine has an analgesic property $[8,10]$. On the other hand, others showed that smoking postoperative increases the pain after tooth extraction [21], and there are clinical evidenceswhich suggests the smokers are at increased risk of developing back pain and other chronic pain disorders [16-19]. However, there has been no previous study in medical literature involving the effect of cigarette smoking on pain in patients undergoing orthodontic treatment. We found that smoking increases pain after the elastomeric separation placement.

Patients were classified as smokers and non-smokers according to the criteria of the World Health Organization [22]. Also, in this study, the patient described as a heavy smoker was approved. According to previous studies, those who smoke more than 20 cigarettes per day [3]. Cigarette smoking has been emphasized as the most common way to deliver nicotine, realizing that other patterns of tobacco use may have comparable effects on pain [22].

The optical digital scale was used to assess pain and despite it being a method that involves some personal factors in assessing pain between different individuals. It is considered one of the most used methods in pain assessment studies and it is reliable to record the amount of pain in a specific time when a large difference is expected between individuals according to systematic reviews [23].

Table 1. Sample Descriptive Statistics.

\begin{tabular}{|c|c|c|c|c|c|c|c|}
\hline \multirow{2}{*}{} & & \multicolumn{2}{|c|}{ Sex } & \multicolumn{4}{c|}{ Age, Years } \\
\cline { 2 - 8 } & $\mathbf{N}$ & Male & Female & Min & Max & Mean & SD \\
\hline Smokers & 20 & 5 & 15 & 18 & 32 & 24.65 & 2.796 \\
\hline Non-smokers & 20 & 16 & 4 & 18 & 31 & 23.3 & 3.31 \\
\hline Total sample & 40 & 21 & 19 & 18 & 32 & 23.98 & 3.101 \\
\hline
\end{tabular}

Table 2. Pain Intensity Differences Between Smokers and Non-Smokers Groups in Rest Mode. (Mann-Whitney).

\begin{tabular}{|c|c|c|c|c|c|}
\hline & \multicolumn{2}{|c|}{ Smokers } & \multicolumn{2}{c|}{ Non-Smokers } & \multirow{2}{*}{ P value } \\
\hline & Mean & SD & Mean & SD & \\
\hline After 1 hour & 1.8 & 0.523 & 1.2 & 0.616 & $0.003^{*}$ \\
\hline After 24 hours & 7.15 & 0.671 & 5.9 & 0.968 & $0.000^{*}$ \\
\hline After 48 hours & 4.58 & 0.813 & 3.85 & 0,813 & $0.001^{*}$ \\
\hline After 7 days & 0.45 & 0.51 & 0.3 & 0.47 & 0.333 \\
\hline
\end{tabular}

* Statistically significant at $\mathrm{P}<.05$.

Table 3. Pain Intensity Differences Between Smokers and Non-Smokers Groups in Chewing Mode. (Mann-Whitney).

\begin{tabular}{|c|c|c|c|c|c|}
\hline & \multicolumn{2}{|c|}{ Smokers } & \multicolumn{2}{c|}{ Non-Smokers } & \multirow{2}{*}{ P value } \\
\cline { 1 - 4 } & Mean & SD & Mean & SD & \\
\hline After 1 hour & 2.85 & 0.671 & 2.2 & 0.616 & $0.002^{*}$ \\
\hline After 24 hours & 8.25 & 0.786 & 7.25 & 0.91 & $0.001^{*}$ \\
\hline After 48 hours & 6.2 & 0.768 & 5.15 & 0.813 & $0.000^{*}$ \\
\hline After 7 days & 0.6 & 0.503 & 0.55 & 0.51 & 0.752 \\
\hline
\end{tabular}

* Statistically significant at $\mathrm{P}<.05$. 
In this study, the pain was evaluated during the chewing process. Studies showed that orthodontic pain appears more aggressively during functions - as in the chewing of foods. On the other hand, other studies selected to evaluate the spontaneous perception of pain with few who evaluated the functional perception of pain.

The peak of orthodontic pain was recorded in both groups (24) hours after the application of elastomeric separation, with lower average pain in the non-smokers' group compared to the smoker's group. Then the pain gradually decreased on the second day and after a week. These results have consisted of the results for other studies that have shown that the pain usually reaches its highest levels after (24) hours after applying the elastomeric separation and then decreases gradually until it fades after (7) days.

It was noted that there wasa statistical significance between the two groups at all measurement times except 7 days after the application of the elastomeric separation. The average pain in smokers recorded a higher value than in non-smoker, therefore smoking increased the pain obtained after (1) hour, (24) hours, and (48) hours of applying the elastomeric separation.

The results of this study have consisted of Larrazábal et al in her study on pain perception after surgical extraction of an impact third molar, which showed that smokers have greater pain scores [21]. As agreed with the results of the Chiang et al study, which showed that smokers required more morphine in the first 72 hours after surgery than did the non-smokers [24].

The difference between the two groups can be explained by the nicotine effect on the sensitivity of $\mathrm{nAChR}$ receptors, smoking abundantly reduces the sensitivity of $\mathrm{nAChR}$ receptors to internal opioids, and therefore, the smokers may be more sensitive to pain, because of the effect of internal opioids may be less in smokers than non-smokers. Thussmokers may require more analgesic drugs to reduce the pain induced by elastomeric separators.

\section{Conclusions}

Cigarette smoking may affect pain induced by elastomeric separators in patients who need orthodontic treatment.

\section{Acknowledgments}

This study was approved by the Institutional Review Board and Ethical Committee of Damascus University (Damascus, Syria) NO 4118.

\section{References}

[1]. Erdinç AM, Dinçer B. Perception of pain during orthodontic treatment with fixed appliances. Eur J Orthod. 2004 Feb; 26(1): 79-85. PMID: 14994886.

[2]. Nóbrega C, da Silva EM, de Macedo CR. Low-level laser therapy for treatment of pain associated with orthodontic elastomeric separator placement: a placebo-controlled randomized double-blind clinical trial. Photomed Laser Surg. 2013 Jan; 31(1): 10-6. PMID: 23153291.

[3]. Schane RE, Ling PM, Glantz SA. Health effects of light and intermittent smoking: a review. Circulation. 2010 Apr 6; 121(13): 1518-22. PMID: 20368531.

[4]. Eslamian L, Borzabadi-Farahani A, Hassanzadeh-Azhiri A, Badiee MR, Fekrazad R. The effect of 810-nm low-level laser therapy on pain caused by orthodontic elastomeric separators. Lasers Med Sci. 2014 Mar; 29(2): 559-
64. PMID: 23334785.

[5]. Polat O, Karaman AI. Pain control during fixed orthodontic appliance therapy. Angle Orthod. 2005 Mar;75(2):214-9. PMID: 15825785.

[6]. Shi Q, Yang S, Jia F, Xu J. Does low level laser therapy relieve the pain caused by the placement of the orthodontic separators?--A meta-analysis. Head Face Med. 2015 Aug 28;11:28. PMID: 26315965.

[7]. Xue Y, Domino EF. Tobacco/nicotine and endogenous brain opioids. Progress in Neuro-Psychopharmacology and Biological Psychiatry. 2008 Jul 1; 32(5):1131-8.

[8]. Jamner LD, Girdler SS, Shapiro D, Jarvik ME. Pain inhibition, nicotine, and gender. Exp Clin Psychopharmacol. 1998 Feb;6(1):96-106. PMID: 9526150 .

[9]. Kanarek RB, Carrington C. Sucrose consumption enhances the analgesic effects of cigarette smoking in male and female smokers. Psychopharmacology (Berl). 2004 Apr; 173(1-2):57-63. PMID: 14722703.

[10]. Marubio LM, del Mar Arroyo-Jimenez M, Cordero-Erausquin M, Léna C, Le Novère N, de Kerchove d'Exaerde A, et al. Reduced antinociception in mice lacking neuronal nicotinic receptor subunits. Nature. 1999 Apr 29; 398(6730): 805-10. PMID: 10235262.

[11]. Pomerleau OF, Turk DC, Fertig JB. The effects of cigarette smoking on pain and anxiety. Addict Behav. 1984; 9(3): 265-71. PMID: 6496202.

[12]. Sahley TL, Berntson GG. Antinociceptive effects of central and systemic administrations of nicotine in the rat. Psychopharmacology (Berl). 1979 Nov; 65(3): 279-83. PMID: 117500.

[13]. Cucchiaro G, Xiao Y, Gonzalez-Sulser A, Kellar KJ. Analgesic effects of Sazetidine-A, a new nicotinic cholinergic drug. Anesthesiology. 2008 Sep; 109(3): 512-9. PMID: 18719450.

[14]. Qian C, Li T, Shen TY, Libertine-Garahan L, Eckman J, Biftu T, Ip S. Epibatidine is a nicotinic analgesic. Eur J Pharmacol. 1993 Dec 21; 250(3): R13-4. PMID: 8112391.

[15]. Spande TF, Garraffo HM, Edwards MW, Yeh HJ, Pannell L, Daly JW. Epibatidine: a novel (chloropyridyl) azabicycloheptane with potent analgesic activity from an Ecuadoran poison frog. Journal of the American Chemical Society. 1992 Apr;114(9):3475-8

[16]. Kaila-Kangas L, Leino-Arjas P, Riihimäki H, Luukkonen R, Kirjonen J. Smoking and overweight as predictors of hospitalization for back disorders. Spine (Phila Pa 1976). 2003 Aug 15;28(16):1860-8. PMID: 12923477.

[17]. Mattila VM, Saarni L, Parkkari J, Koivusilta L, Rimpelä A. Predictors of low back pain hospitalization--a prospective follow-up of 57,408 adolescents. Pain. 2008 Sep 30;139(1):209-217. PMID: 18472217.

[18]. Miranda H, Viikari-Juntura E, Punnett L, Riihimäki H. Occupational loading, health behavior and sleep disturbance as predictors of low-back pain. Scand J Work Environ Health. 2008 Dec;34(6):411-9. PMID: 19137202.

[19]. Weingarten TN, Podduturu VR, Hooten WM, Thompson JM, Luedtke CA, Oh TH. Impact of tobacco use in patients presenting to a multidisciplinary outpatient treatment program for fibromyalgia. Clin J Pain. 2009 Jan; 25(1): 39-43. PMID: 19158544.

[20]. Hooten WM, Townsend CO, Bruce BK, Schmidt JE, Kerkvliet JL, Patten CA, Warner DO. Effects of smoking status on immediate treatment outcomes of multidisciplinary pain rehabilitation. Pain Med. 2009 Mar;10(2):347-55. PMID: 18721171.

[21]. Larrazábal C, García B, Peńarrocha M, Peńarrocha M. Influence of oral hygiene and smoking on pain and swelling after surgical extraction of impacted mandibular third molars. J Oral Maxillofac Surg. 2010 Jan; 68(1): 43-6. PMID: 20006153.

[22]. World Health Organization. Guidelines for the conduct of tobacco smoking survey of the general population: report of a WHO meeting held in Helsinki, Finland, 29 November-4 December 1982. World Health Organization; 1983.

[23]. Stinson JN, Kavanagh T, Yamada J, Gill N, Stevens B. Systematic review of the psychometric properties, interpretability and feasibility of self-report pain intensity measures for use in clinical trials in children and adolescents. Pain. 2006 Nov;125(1-2):143-57. PMID: 16777328.

[24]. Chiang HL, Chia YY, Lin HS, Chen CH. The implications of tobacco smoking on acute postoperative pain: a prospective observational study. Pain Research and Management. 2016 Mar 29; 2016. 